Article

\title{
Nonylphenol Ethoxylate Surfactants Modified by Carboxyl Groups for Foam EOR at High-Salinity Conditions
}

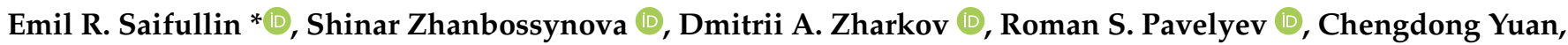 \\ Mikhail A. Varfolomeev $\mathbb{D}^{0}$, Ulukbek Zh. Mirzakimov, Sergey Yu. Ivanov and Sergey A. Sitnov
}

Department of Petroleum Engineering, Kazan Federal University, 420008 Kazan, Russia; sk.zhanbossynova@gmail.com (S.Z.); dm-zharkov@yandex.ru (D.A.Z.); rpavelyev@gmail.com (R.S.P.); swpuycd@gmail.com (C.Y.); vma.ksu@gmail.com (M.A.V.); mirzakimovqs@gmail.com (U.Z.M.); liojeg@bk.ru (S.Y.I.); sers11@mail.ru (S.A.S.)

* Correspondence: mr.emilsr@gmail.com

\section{check for} updates

Citation: Saifullin, E.R.; Zhanbossynova, S.; Zharkov, D.A.; Pavelyev, R.S.; Yuan, C.; Varfolomeev, M.A.; Mirzakimov, U.Z.; Ivanov, S.Y.; Sitnov, S.A. Nonylphenol Ethoxylate Surfactants Modified by Carboxyl Groups for Foam EOR at High-Salinity Conditions. Energies 2021, 14, 8205. https://doi.org/ $10.3390 /$ en14248205

Academic Editor: Rouhi Farajzadeh

Received: 29 October 2021

Accepted: 3 December 2021

Published: 7 December 2021

Publisher's Note: MDPI stays neutral with regard to jurisdictional claims in published maps and institutional affiliations.

Copyright: (c) 2021 by the authors. Licensee MDPI, Basel, Switzerland. This article is an open access article distributed under the terms and conditions of the Creative Commons Attribution (CC BY) license (https:// creativecommons.org/licenses/by/ $4.0 /)$.

\begin{abstract}
High mineralization of water complicates the use of foam in reservoir conditions. Anionicnonionic surfactants are one of the best candidates for these conditions since they have both high surface activity and salt tolerance. One of the ways to obtain anionic-nonionic surfactants is to modify nonionic surfactants by an anionic group. The type of the group and its chemical structure can strongly affect the properties of the surfactant. In this work, widely-produced nonionic surfactant nonylphenol (12) ethoxylate (NP12EO) was modified by new types of carboxylic groups through the implementation of maleic (NP12EO-MA) and succinic (NP12EO-SA) anhydrides with different saturation levels. The main objectives of this work were to compare synthesized surfactants with nonionic precursor and to reveal the influence of unsaturated bonds in the carboxyl group on the properties of the foam. $\mathrm{NaCl}$ concentration up to $20 \mathrm{wt} \%$ was used to simulate high mineralization conditions, as well as to assess the effect of unsaturated bonds on foam properties. Synthesized anionic-nonionic surfactants retained surfactant solubility and long-term stability in high-salinity water, but have better foaming ability, as well as higher apparent viscosity, in porous media. The presence of an unsaturated bond in NP12EO-MA surfactant lowers foaming ability at high mineralization.
\end{abstract}

Keywords: foam; surfactant; carboxylated ethoxylated nonylphenol; chemical EOR; high-salinity water

\section{Introduction}

For the last decades, the foam was used for improved oil recovery (IOR) and enhanced oil recovery (EOR) technologies, such as acid treatment [1,2], gas mobility control [3], foam-assisted water altering gas injection [4], gas shut-off [5], etc. In all EOR technologies, foam should create stable multiphase media with high apparent viscosity for gas conformance control and gas phase permeability decreasing. Producing stable foam for oilfield applications surfactants should be compatible with the formation water or brine to create stable aqueous foam.

One of the challenges for foam EOR nowadays is the development or selection of effective reagents for carbonate reservoirs, characterized by high water salinity [6,7]. The most widely applied surfactants in carbonate reservoirs are related to the nonionic type with high salt tolerance [8-12], which mainly belongs to ethoxylated and/or propoxylated fatty alcohols, fatty amines, and alkylphenols with different quantities and ratios of alkoxy groups. Depending on the hydrophilic-lipophilic balance and length of an ethoxylated group [13], nonionic surfactants can have good solubility and stability in high-salinity water. However, nonionic surfactants showed low foaming ability, compared to ionic type surfactants [14-17]. Comparison made by Li et al. [18] of three types of surfactant: nonionic, anionic and anionic-nonionic, showed that anionic-nonionic surfactant created foam with higher stabilized pressure during filtration tests and higher foam elasticity than others. 
The absence of charge in nonionic surfactants molecules in the gas-water-gas adsorption layers decreases disjoining pressure and foam elasticity.

Nonylphenol ethoxylate (NPEO) is one of the most produced nonionic surfactants, which is used for decades as household cleaning products $[19,20]$, for micellar extraction of residues from water [21-23], and chemical EOR [24,25]. Several works showed improved performance of NPEO surfactants modified by different ionic groups, including carboxyl, sulfonate, sulfate groups [26-32]. An addition of ionic groups in nonionic surfactant molecules increases surfactant surface activity and cloud point temperature. Interfacial tension less than $10^{-2} \mathrm{mN} / \mathrm{m}$ was achieved [33] between crude oil from Shengli oilfield and nonylphenol polyoxyethylene (6) ether carboxylate surfactant solution. Alkyl ether carboxylate with an average polyethoxylated length of three showed high interfacial activity in the presence of $\mathrm{Na}^{+}, \mathrm{Ca}^{2+}$ and $\mathrm{Mg}^{2+}$ counterions [34]. Spontaneous oil displacement experiments of several ionic-nonionic type surfactants showed the high efficiency of ethoxylated sulfonates [35]. However, known works focused mainly on the oil/water interface activity of NPEO modified surfactants, and only a few works were devoted to gas/water surface [36-38].

In this paper, performance of two novel anionic-nonionic surfactants based on nonylphenol (12) ethoxylate (NP12EO) as foaming agents at $\mathrm{NaCl}$ up to $20 \mathrm{wt} \%$ concentrations were tested. Obtained nonylphenol ethoxylate maleate (NP12EO-MA) and succinate (NP12EO-SA) surfactants were evaluated by foam rate, foam half-life time, surface tension, and foam apparent viscosity in porous media. All chemicals for synthesis are widely produced and relatively cheap, making novel surfactants great candidates for application in high-salinity carbonate reservoirs.

\section{Materials and Methods}

\subsection{Materials}

A nonionic surfactant nonylphenol ethoxylate (NP12EO) with an average number of ethoxy groups in a molecule equal to 12 was used as the precursor for synthesis. NP12EO was provided by Nizhnekamskneftekhim (Russia) petrochemical company with a purity of not less than $98 \%$. Maleic anhydride $(99 \%)$ and succinic anhydride $(99 \%)$ were obtained from Acros Organics BVBA and Merck KGaA. Triethylamine (99.7\%) was provided by Vecton company (Russia). $\mathrm{NaCl}(99.5 \%)$ was provided by JSC LenReactiv. Sodium dodecyl sulfate ( $98 \%$ ) as a reference surfactant was obtained from Spektr-Khim company (Russia). All chemicals were used and received without any further purification.

\subsection{General Procedure for Surfactant Synthesis and Characterization}

Surfactants were synthesized by following the method outlined in Scheme 1. NP12EO (10 gr, $13.37 \mathrm{mmol})$ and anhydrides $(13.37 \mathrm{mmol})$ were charged in a $100 \mathrm{~mL}$ reaction flask. This mixture was stirred for $5 \mathrm{~h}$ at $70{ }^{\circ} \mathrm{C}$. The intermediate compounds $1 \mathrm{a}$ and $1 \mathrm{~b}$ were used without any further purification. In the next stage, products $(14.20 \mathrm{mmol})$ were neutralized with $\mathrm{NaHCO}_{3}(14.30 \mathrm{mmol})$ and the reaction mixture was stirred $5 \mathrm{~h}$ more at $70{ }^{\circ} \mathrm{C}$. Pale-yellow viscous products were obtained. Synthesized compounds with maleic 2a (NP12EO-MA) and succinic $2 \mathrm{~b}$ (NP12EO-SA) anhydrides were used further without any purification. 

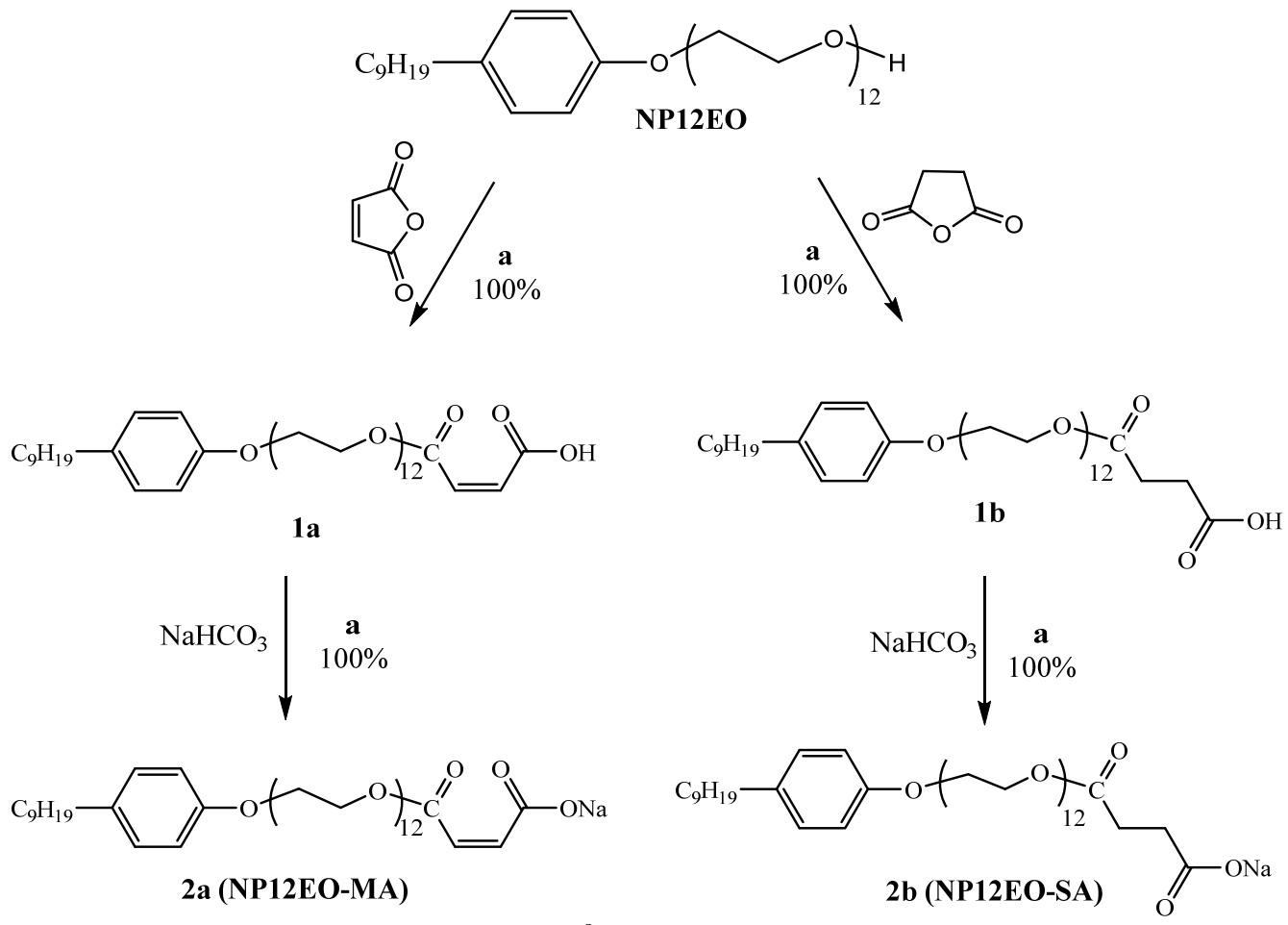

a) $70{ }^{\circ} \mathrm{C}, 5 \mathrm{~h}$, solvent free

Scheme 1. Synthesis of NP12EO-MA and NP12EO-SA.

\subsection{Solubility and Stability}

To test the applicability in high salinity water, $20 \mathrm{~mL}$ solutions of surfactants with $0.5 \%$ concentration at different $\mathrm{NaCl}$ concentrations were prepared. The solubility of surfactants was tested after $30 \mathrm{~min}$ of mixing. After that, solutions were placed into the oven for 30 days at a temperature of $293 \mathrm{~K}$ for the stability test. Color of solutions, phase separation and precipitation were inspected visually at both stages.

\subsection{CMC Determination}

It is well known that critical micelle concentration (CMC) is an important parameter for understanding the effective concentration above which the properties of foam usually do not change totally or do not change significantly. Several methods allow the determination of the CMC point, including conductometric, dynamic light scattering, viscometric, refractometric, and surface tension methods [30,39]. Surface tension (SFT) of solutions at different concentrations of surfactant were measured at $293 \mathrm{~K}$ by the pendant drop method in a programmable drop shape analyzer (Krüss DSA-100HP40). Each point was measured three times and an average value was used for analysis. The CMC point was determined as the surfactant concentration at which the sharp change in the SFT rate (dSFT) decreases by more than 10 times the initial rate. dSFT is the first derivative of the surface tension (SFT) change function from the surfactant concentration.

\subsection{Foam Rate and Half-Life Time}

The foaming ability of synthesized surfactants was compared with initial nonionic surfactant NP12EO and one of the most studied surfactants-sodium dodecyl sulfate (SDS). The micellar solutions with a concentration of surfactant approximately 25 times more than observed CMC were chosen for bulk foam tests according to the previous experience [39,40]. NP12EO, NP12EO-MA, NP12EO-SA, and SDS surfactants solutions at $0.5 \mathrm{wt} \%$ concentration with a volume of $100 \mathrm{~mL}$ were prepared in distilled water and water with different concentrations of $\mathrm{NaCl}$ to determine the foam rate and foam half-life time. The foam was generated in an overhead stirrer at a rotation speed of $2000 \mathrm{rpm}$ for $10 \mathrm{~min}$. 
The foam rate was measured in a $1000 \mathrm{~mL}$ measuring cylinder to determine the foam rate, which was defined as the ratio of the generated foam volume to the volume of the initial surfactant solution. The foam half-life time was measured as the time from the end of foam generation until the volume of the surfactant solution in the cylinder increased to $50 \mathrm{~mL}$ as a result of the liquid drainage and foam destruction $(50 \mathrm{vol} \%$ of the initial volume of the surfactant solution). All the experiments were provided at room temperature.

\subsection{Filtration Experiments}

The efficiency of surfactants as foaming agents can also be estimated by the apparent viscosity of foam, which was determined by filtration tests in a porous medium [41]. Values of apparent viscosity also help to determine the optimal gas/liquid ratio. Artificial silicatetype core samples based on consolidated quartz sand were used in the experiments as homogeneous porous media. The dimensions of the artificial core samples were $5 \mathrm{~cm}$ in length and $3 \mathrm{~cm}$ in diameter. The average absolute gas permeability was 1 Darcy, and the average porosity was $13 \%$. The most common gases used in gas and chemical methods are carbon dioxide $\left(\mathrm{CO}_{2}\right)$, nitrogen $\left(\mathrm{N}_{2}\right)$ and hydrocarbon gases [42-45]. Due to the high inertness of nitrogen, to compare the properties of foams in a porous medium, the high-purity nitrogen $(99.999 \%)$ was used as the gas phase for generating foam, as well as a displacing agent. The filtration experiments were performed on the filtration setup according to the scheme shown in Figure 1.

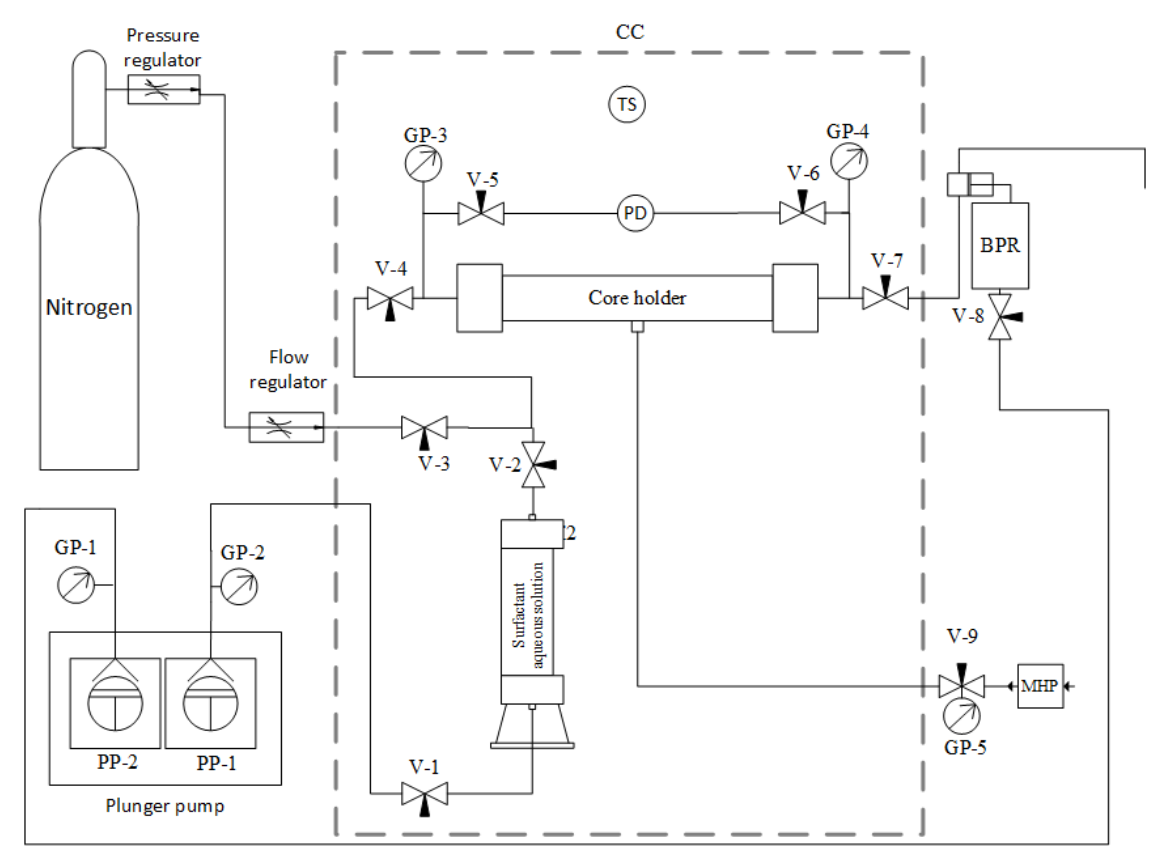

Figure 1. Scheme of the filtration setup: V—valves, GP—gauge pressure sensors, PD—pressure drop sensor, MHP-manual hydraulic pump, BPR—back pressure regulator, TS—temperature sensor, CC-climate chamber.

The experiments were carried out under the following conditions: reservoir pressure 50 bar and temperature $20^{\circ} \mathrm{C}$. Overburden pressure was maintained 30 bar higher than reservoir pressure to simulate lithostatic pressure and prevent liquid and gas crossflows. The liquid was injected through a piston-cylinder using a plunger hydraulic pump with an accuracy of $0.001 \mathrm{~mL} / \mathrm{min}$. The reservoir pressure was maintained by a piston-type back pressure regulator with a needle valve. The inlet and outlet pressures of the core holder, as well as the differential pressure, were measured using digital gauge pressure sensors (measurement accuracy 0.01 bar). Pressure data were continuously recorded on a computer. The nitrogen flow rate was controlled by a Bronkhorst EL-FlOW gas flow meter with an accuracy of $0.05 \mathrm{~mL} / \mathrm{min}$. 
The core was saturated with $20 \% \mathrm{NaCl}$ water under vacuum and placed in a coreholder. Saline water was pumped through the core to determine the absolute permeability of water. In the next stage, the solution of surfactant in an amount of at least three pore volumes (PV) was pumped through the sample to saturate the core and minimize the effect of surfactant adsorption on the core surface, and accelerate foam flow stabilization. After that, surfactant solution and gas were co-injected in the core to generate foam. The total volumetric flow rate in the experiments was $2 \mathrm{~mL} / \mathrm{min}$. The ratio of gas and surfactant solution in the total injected flow rate was determined by the foam quality $\left(f_{g}\right)$ parameter. Foam quality equal to the ratio of the gas volumetric flow rate to the total volumetric gas-liquid flow rate (1):

$$
f_{g}=q_{g} /\left(q_{g}+q_{l}\right)
$$

where $q_{g}$-the volumetric flow of nitrogen, and $q_{l}$-volumetric flow rate of foaming solution.

To determine optimal foam quality, apparent viscosity $\left(\mu_{\text {app }}^{F}\right)[41,46]$ of foam was measured at $f_{g}=0.35,0.5,0.65,0.8$, and 0.95 . Apparent viscosity of foam was determined by Formula (2):

$$
\mu_{\text {app }}^{F}=\left(k_{a b s} \times A \times \Delta P\right) /\left[\left(q_{g}+q_{l}\right) \times L\right],
$$

where $k_{a b s}$-absolute permeability by $20 \% \mathrm{NaCl}$ mineralization water, $A$-core cross-section area, $\Delta P$-stabilized pressure drops during foam injection, and $L$-core length.

\section{Results and Discussion}

\subsection{Surfactants Synthesis and Characterization}

Surfactant synthesis was provided according to Scheme 1. Initial reagents are cheap and widely-produced compounds. All chemicals were used and received without any further purification. Reactions occurred in soft conditions without solvent and separation of $1 \mathrm{a}$ and $1 \mathrm{~b}$ components.

The structure of NP12EO-MA and NP12EO-SA were confirmed by NMR and HRMS methods. All necessary signals are present in the ${ }^{1} \mathrm{H}$ NMR spectra of both surfactants. So, in the area of $6 \mathrm{ppm}$, NP12EO-MA spectra contain proton signals at the double bond of the maleic fragment. Additionally, in the NP12EO-SA spectra in the region of about $2.5 \mathrm{ppm}$, there is a double signal of two methylene fragments of the succinic acid residue.

\subsection{Solubility and Stability}

Results of the tests showed that NP12EO-MA and NP12EO-SA surfactants, as well as initial nonionic surfactant NP12EO, were dissolved in water with mineralization of up to $20 \mathrm{wt} \% \mathrm{NaCl}$, and solutions remained transparent for a long time (Figure 2). However, at $\mathrm{NaCl}$ concentrations of $10 \mathrm{wt} \%$ and $20 \mathrm{wt} \%$, precipitation of SDS occurred.

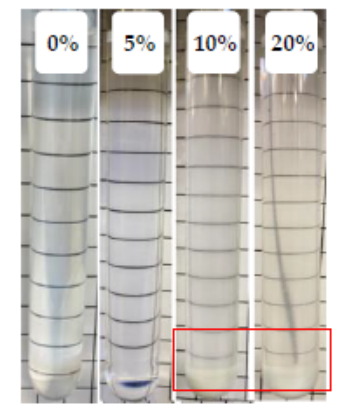

(a)

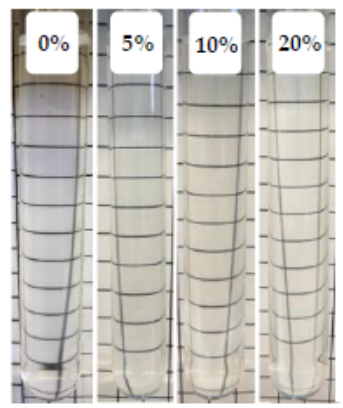

(b)

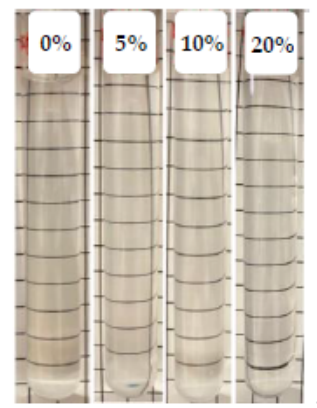

(c)

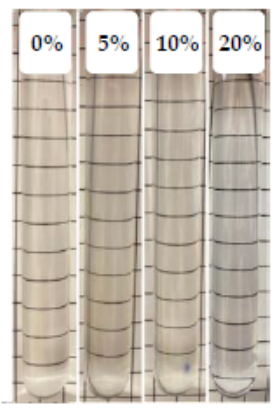

(d)

Figure 2. The appearance of surfactant solutions at $0,5,10$ and $20 \mathrm{wt} \% \mathrm{NaCl}$ concentrations after 30 days at $293 \mathrm{~K}$ : (a) SDS; (b) NP12EO, (c) NP12EO-SA; (d) NP12EO-MA. 


\subsection{Foam Rate and Half-Life Time}

The foaming ability of all surfactants was evaluated according to foam rate and halflife time of foam (Figures 3 and 4). To compare foaming ability, one of the most studied surfactants sodium dodecyl sulfate (SDS) was used as a reference surfactant. Immediately after the foam generation, the liquid starts to drain from lamellas as a result of gravitational forces. At this time, gas/liquid ratio is low, lamellas thickness is too high, and capillary forces do not have a significant effect. The liquid flows down the walls of the films until the capillary forces become equal to disjoining pressure due to the repulsion forces of ionic surfactants or the steric effect of nonionic surfactants. At this time, the liquid tends from the lamellae towards the nodes. However, the "retention" of the liquid occurs with different forces depending on the type of surfactant, because of different thicknesses of the lamellae, as well as different values of the Van der Waals forces and the presence of a charge in anionic surfactants. All these points directly affect the half-life time of the foam.

SDS showed a higher foam rate and foam half-life time at low $\mathrm{NaCl}$ concentrations, but generated no foam at higher mineralization due to surfactant precipitation. Ethoxylate surfactants showed a more stable foam rate which slowly decreased with increasing $\mathrm{NaCl}$ concentration.

Compared with NP12EO, synthesized surfactants showed a higher foam rate at all $\mathrm{NaCl}$ concentration ranges, but no significant difference in half-life time was observed. At $20 \mathrm{wt} \%$ concentration of $\mathrm{NaCl}$, both anionic-nonionic surfactants can still generate foam with a foam rate above 4.5 , and the initial nonionic surfactant NP12EO can achieve only 3.5. A slight increase in foam rate at $5 \mathrm{wt} \% \mathrm{NaCl}$ can be described by increasing the adsorption rate of anionic-nonionic surfactant molecules in the interfacial surface. At higher $\mathrm{NaCl}$ concentration, the adsorption rate of surfactants reaches its maximum level and $\mathrm{Na}^{+}$cations only decrease repulsive forces [47]. Further increasing of $\mathrm{NaCl}$ concentration leads to a decrease of foam rate of both synthesized surfactants. However, a significant difference was not noticed between synthesized surfactants at all mineralization ranges. According to the measurements (Figure 4), generally, the half-life time of both synthesized surfactants increases with $\mathrm{NaCl}$ concentration. However, at $5 \% \mathrm{NaCl}$ concentration, half-life time of anionic-nonionic surfactants decreased or remained the same. The same effect was observed in the work of [48], where authors considered liquid drainage in lamellas versus $\mathrm{NaCl}$ concentration. The authors showed that in the $\mathrm{NaCl}$ concentration ranges from $0 \mathrm{wt} \%$ to $18 \mathrm{wt} \%$, the maximum rate of drainage was obtained at $5 \mathrm{wt} \% \mathrm{NaCl}$. Further increasing of foam half-life time at higher $\mathrm{NaCl}$ concentrations was also described by bubbles coalescence time increasing due to decreasing of surface tension [49].

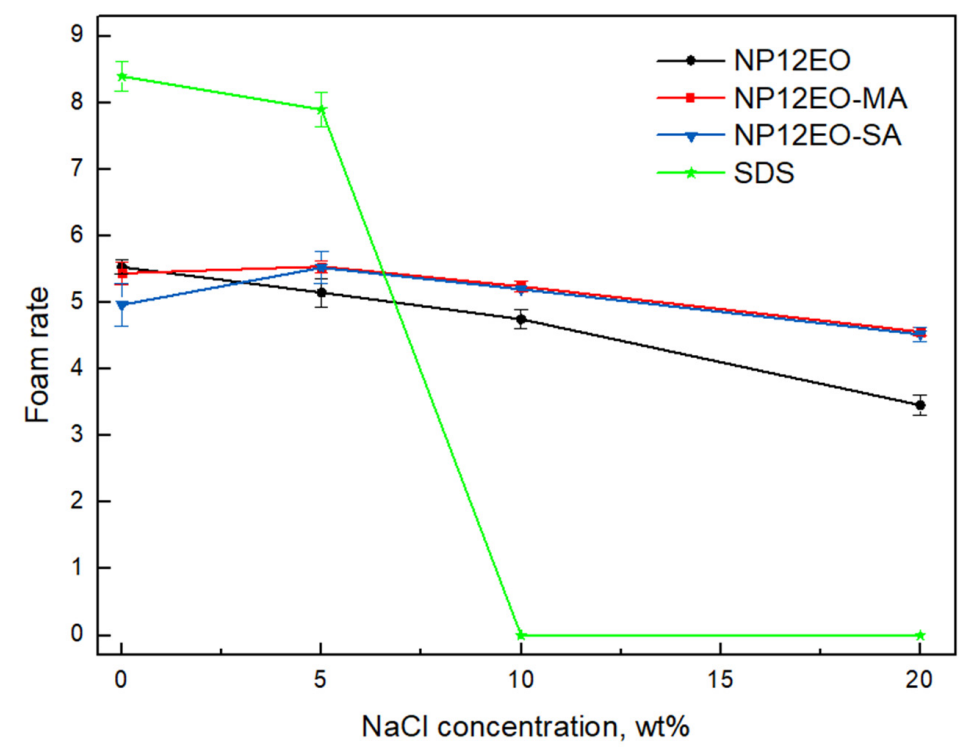

Figure 3. Foam rate of surfactants at $0,5,10$, and $20 \mathrm{wt} \%$ of $\mathrm{NaCl}$ concentrations. 


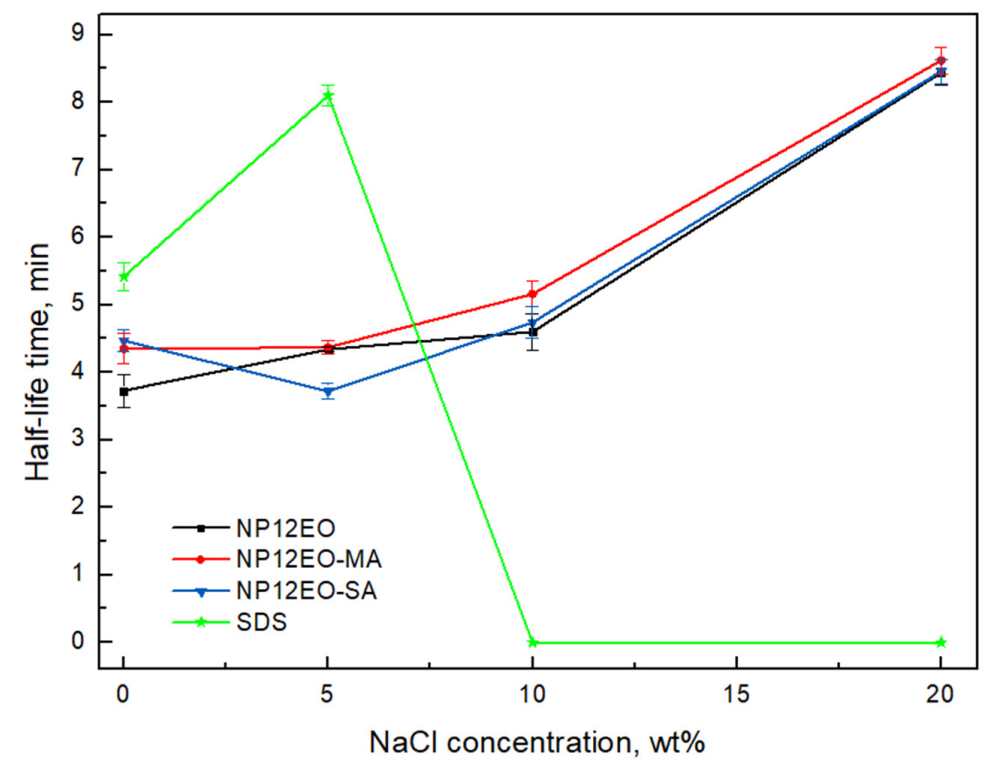

Figure 4. Foam half-life time at $0,5,10$, and $20 \mathrm{wt} \%$ of $\mathrm{NaCl}$ concentrations.

Achieved foam rate and half-life time values of modified surfactants are comparable with salt-tolerance surfactants, such as cocamido-propyl hydroxyl sulfobetaine, with a foam rate value of about 6 and a half-life time of about $3 \mathrm{~min}$ [50].

\subsection{CMC Determination}

In Figure 5, the effect of surfactants addition in distilled water on the surface tension (SFT) at $293 \mathrm{~K}$ and atmospheric pressure can be seen. In distilled water, the surface tension of all surfactants decreases rapidly and reaches its stable SFT values at a concentration of less than $0.025 \mathrm{wt} \%$. According to dSFT values, NP12EO-SA, NP12EO-MA and NP12EO reach $\mathrm{CMC}$ at $0.02 \mathrm{wt} \%, 0.015 \mathrm{wt} \%$ and $0.015 \mathrm{wt} \%$, respectively.

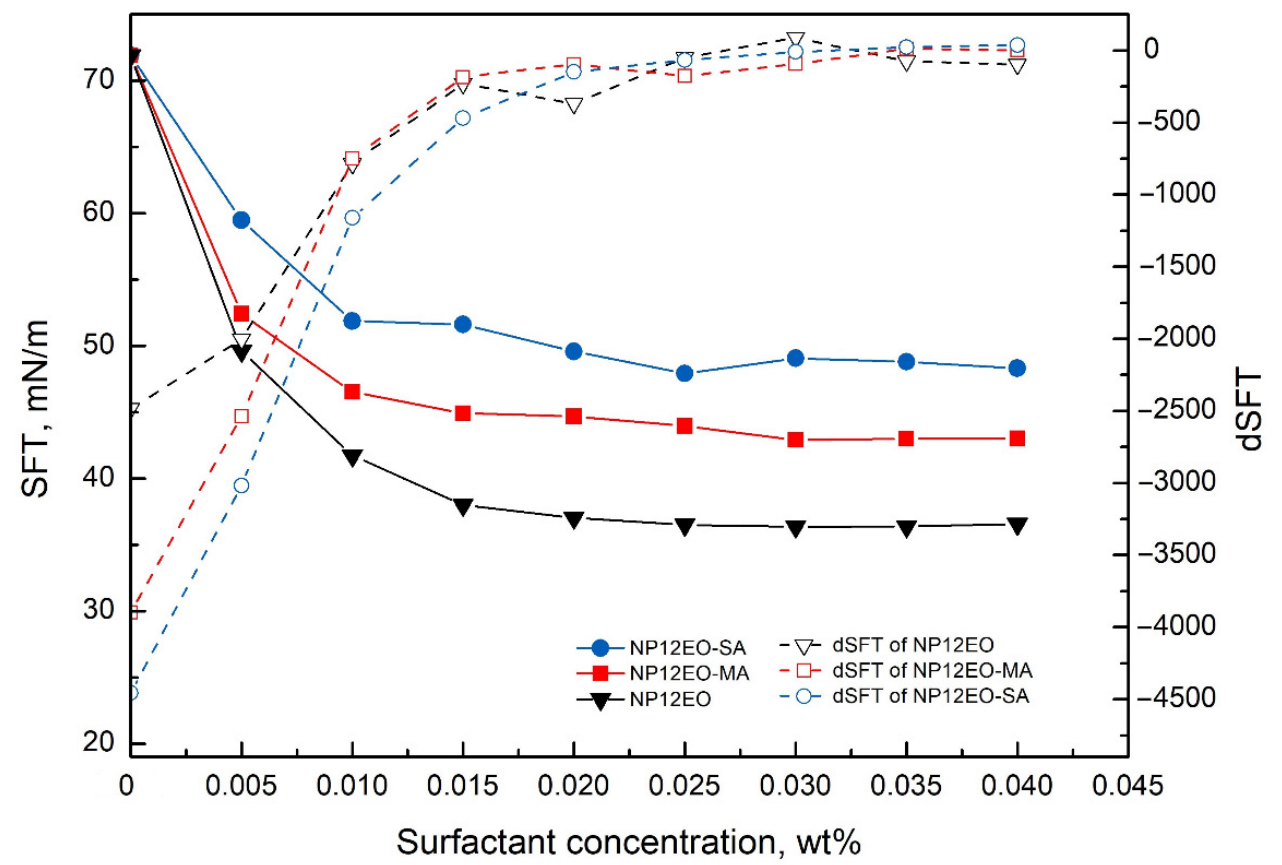

Figure 5. The surface tension of NP12EO-SA, NP12EO-MA, and NP12EO surfactant solutions on distilled water. 
CMC of all surfactants was also measured at three $\mathrm{NaCl}$ concentrations (Table 1). Synthesized surfactants showed higher or the same CMC values than nonionic NP12EO due to the higher hydrophilicity of modified surfactants. The addition of $\mathrm{NaCl}$ led to a decrease in the surface tension, which was noticeable for all surfactants, and, in turn, reduced the CMC. The presence of $\mathrm{Na}^{+}$cations decreases the ionic charge of the ionic part of the molecule that leads to an increase of hydrophobicity of surfactant and increases the interaction between hydrophobic groups (nonylphenol). Consequently, micelles start to form at lower surfactant concentrations. Besides, with increasing $\mathrm{Na}^{+}$concentration, hydration of ethoxy groups occurs, which leads to amplification of the hydrophobic interaction ("salting-out effect" $^{\prime \prime}$. All these effects were discussed in the works [51,52] at $\mathrm{NaCl}$ concentration ranges up to $5 \mathrm{wt} \%$.

Table 1. CMC of surfactant NP12EO-SA, NP12EO-MA, and NP12EO at different NaCl concentrations.

\begin{tabular}{cccc}
\hline \multirow{2}{*}{ NaCl, wt $\%$} & \multicolumn{3}{c}{ Critical Micelle Concentration, wt $\%$} \\
\cline { 2 - 4 } & NP12EO-SA & NP12EO-MA & NP12EO \\
\hline 0 & 0.02 & 0.015 & 0.015 \\
5 & 0.015 & 0.01 & 0.01 \\
10 & 0.01 & 0.01 & 0.0075 \\
20 & 0.0075 & 0.0075 & 0.0075 \\
\hline
\end{tabular}

The decrease in surface tension is directly related to the number of surfactant molecules adsorbed at the water-gas interface. The addition of $\mathrm{NaCl}$ salt increases the number of molecules adsorbed due to repulsion reduction between the surfactant head groups, which results in closer packing. This was also described by some authors [53].

In addition, Zhang et al. described the effect of $\mathrm{NaCl}$ hydration in water on surface tension. When salt ions hydrate, they take water molecules, thus increasing the effective concentration of surfactant. In its turn, this leads to a decrease of surface tension and consequently CMC [54].

The CMC values of synthesized surfactants lied in the relatively low ranges. The CMC of synthesized NP12EO-SA and NP12EO-MA $\left(0.8621 \cdot 10^{-4}\right.$ and $\left.0.8641 \cdot 10^{-4} \mathrm{~mol} / \mathrm{L}\right)$ in $20 \mathrm{wt} \% \mathrm{NaCl}$ are twice lower than ethoxylated betaines in formation water with a total mineralization of $214 \mathrm{~g} / \mathrm{L}\left(1.65 \times 10^{-4}\right.$ and $\left.2.20 \times 10^{-4}\right)$ [53].

The effect of $\mathrm{NaCl}$ on the surface tension at the $\mathrm{CMC}$ point $\left(\gamma_{\mathrm{CMC}}\right)$ is shown in Figure 6. In general, for all surfactants, a sharp decrease of SFT during $\mathrm{NaCl}$ concentration increasing was observed. It is well known that the mineralization of solution strongly affects surface tension values [45]. From the obtained results, the sodium chloride concentration affects more on the surface tension of surfactants with the ionic group due to the increasing concentration of adsorbed surfactants in the interfacial boundary; the higher number of molecules of surfactants, the less SFT [55]. However, there is a slight difference in SFT values between synthesized surfactants: at $0.015 \mathrm{wt} \%$ SFT of NP12EO-MA is $45 \mathrm{mN} / \mathrm{m}$, while the SFT of NP12EO-SA at $0.02 \mathrm{wt} \%$ is only $50 \mathrm{mN} / \mathrm{m}$. 


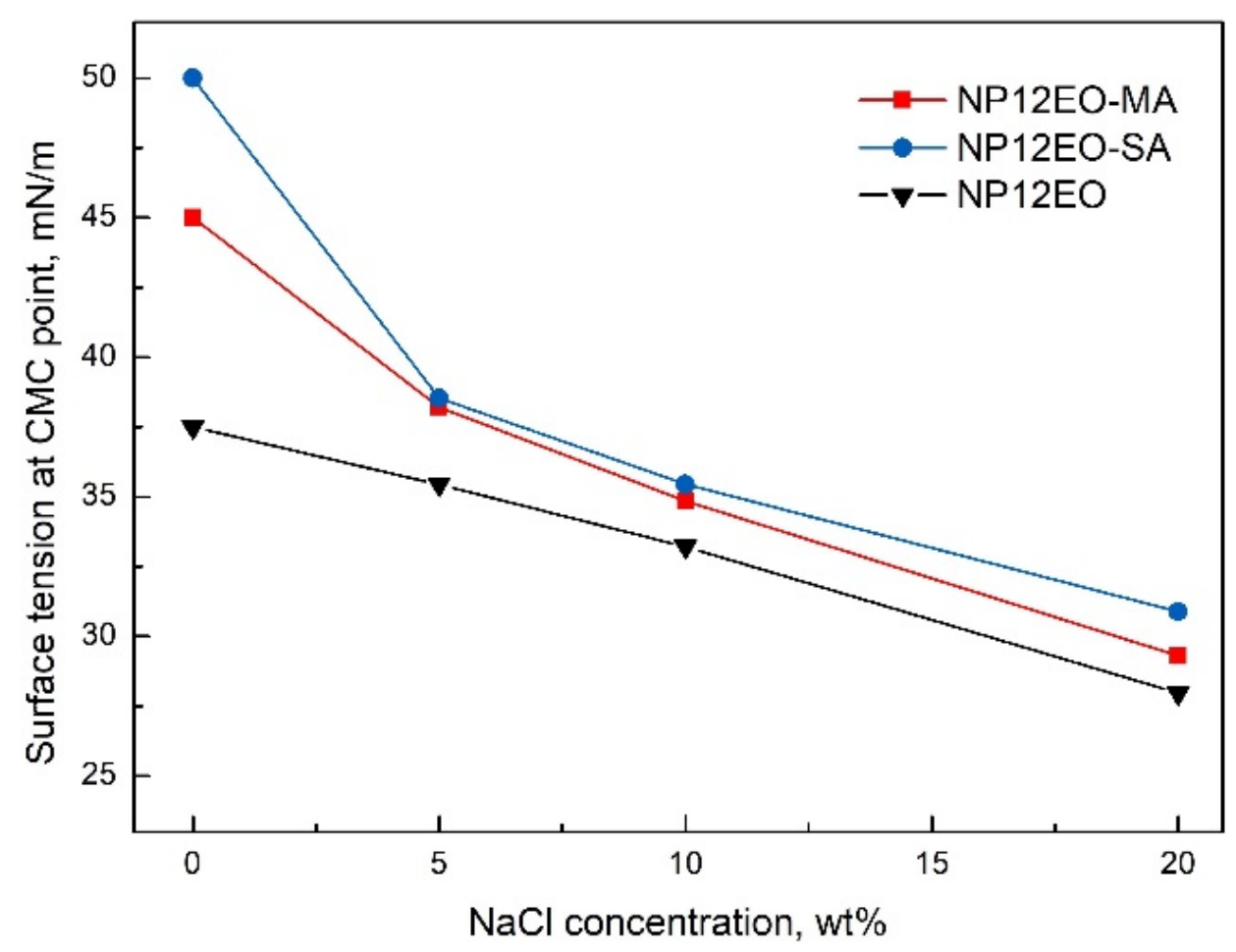

Figure 6. Surface tension at CMC point $\left(\gamma_{\mathrm{CMC}}\right)$ of NP12EO-SA, NP12EO-MA, and NP12EO.

\subsection{Determination of Optimal Foam Quality and Apparent Viscosity of the Foam}

The apparent viscosity of foams in porous media for each $f_{g}$ (Figure 7, Table 2) was calculated Equation (1) for both synthesized and initial nonionic surfactant after the stabilization of the pressure drop. The highest apparent viscosities of a synthesized surfactant were obtained at $f_{g}=0.5$, for NP12EO at $f_{g}=0.65$. Depending on shear rate, foam can exhibit shear-thinning and shear-thickening behavior [56] that mostly appear at a lower or higher foam quality range. At foam quality range $f_{g}=0.5-0.65$, the apparent viscosity of the foam has minimum dependence on shear rate [57] which was chosen as optimal foam quality. At this range of apparent viscosity, foam can be used in a fairly wide range of injection rates.

The subsequent increase in a gas amount at the high quality of foam leads to a decrease of apparent viscosity till 4-27 cP due to foam draining [46]. At this regime, lamellas become thinner and foam behavior depends mostly on the influence of surfactant molecules on foam stability. At low foam qualities, the apparent viscosity of the foam decreased because it starts to behave as a colloid system with continuous liquid phase and particles (gas bubbles) without much interaction between them [58].

Synthesized surfactants reached more than 1.5 times higher apparent viscosities than nonionic NP12EO (Table 2 ) at all ranges of foam quality $\left(f_{g}\right)$. These results showed improvement in foam properties of anionic-nonionic surfactants. The lower apparent viscosity of foam generated by NP12EO-MA surfactant represents the effect of the unsaturated bond in the ionic part of synthesized surfactants. The presence of an unsaturated bond in the NP12EO-MA increases surfactant adsorption surface area due to molecule geometry. Thus, in the fragment of succinic acid of the NP12EO-SA molecule, free rotation around a single $\mathrm{C} 2-\mathrm{C} 3$ bond is possible. This allows this molecule to adopt a conformation that promotes the densest packing of NP12EO-SA molecules at the phase interface. At the same time, in the NP12EO-MA molecule in the maleic acid fragment around the double bond at C2-C3, rotation is difficult. This leads to the impossibility of dense packing of the molecules of this surfactant at the phase interface due to the presence of the cis-geometry of the hydrophilic fragment of maleic acid, which will occupy a larger area compared to the similar hydrophilic fragment of succinic acid in the NP12EO-SA molecule. Decreasing 
the adsorption rate of surfactant molecules in the interfacial layer decreases foaming ability and foam apparent viscosity. Moreover, the closer the foam quality to optimal $\left(f_{g}=0.5-0.8\right)$, the highest difference in the obtained apparent viscosities values. Filtration experiments correlate with bulk test results (Figure 3), where synthesized anionic-nonionic surfactants showed a higher foam rate than nonionic NP12EO.

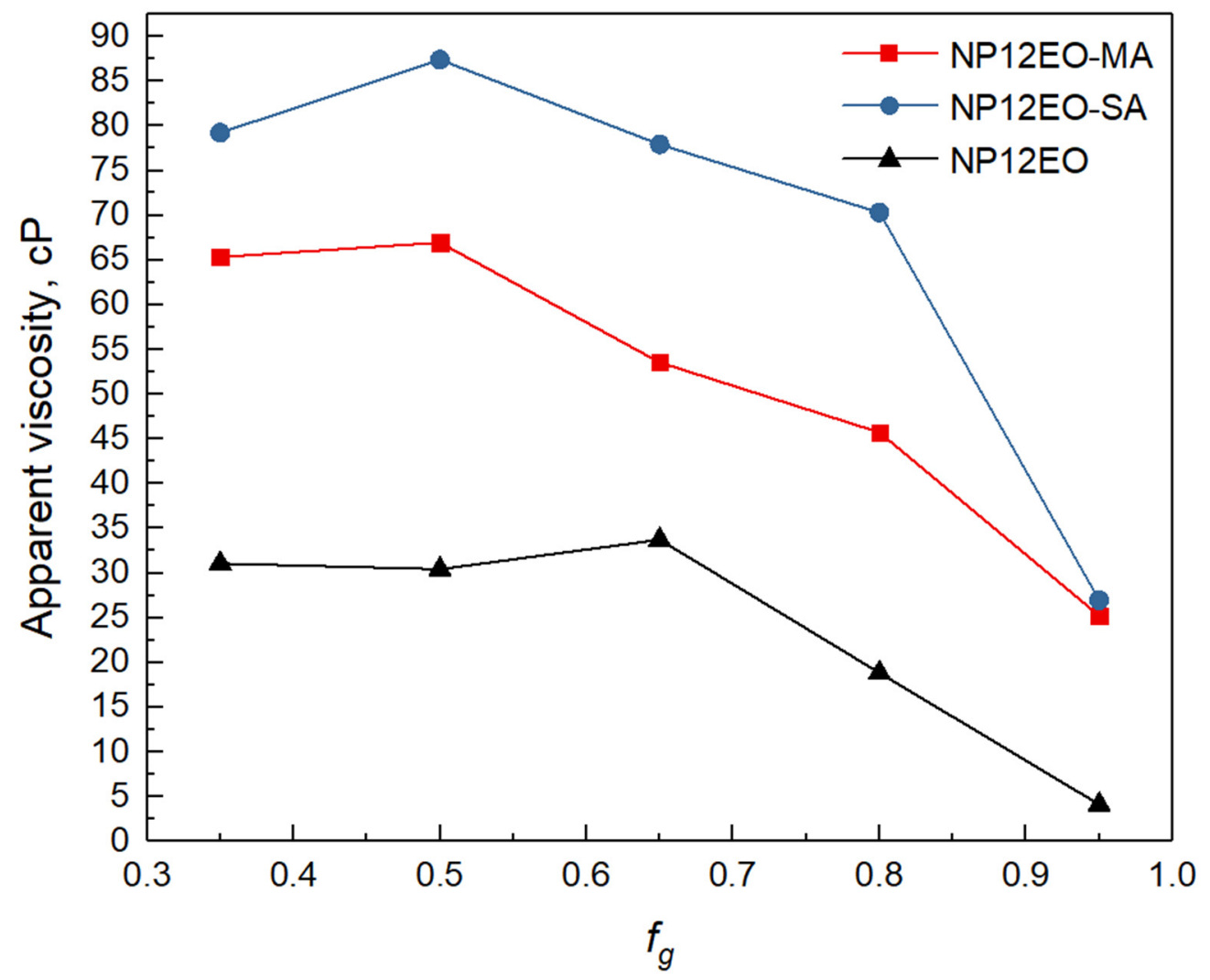

Figure 7. Foam quality scan results for surfactant solutions of $20 \% \mathrm{NaCl}$.

Table 2. Apparent viscosity $\left(\mu^{F}\right.$ app $)$ and pressure drop $(\Delta P)$ values of foams at different foam quality $\left(f_{g}\right)$.

\begin{tabular}{ccccccc}
\hline \multirow{2}{*}{ Surfactant } & \multirow{2}{*}{ Parameter } & \multicolumn{5}{c}{ Foam Quality $\left(f_{g}\right)$} \\
\cline { 3 - 7 } & & $\mathbf{0 . 3 5}$ & $\mathbf{0 . 5}$ & $\mathbf{0 . 6 5}$ & $\mathbf{0 . 8}$ & $\mathbf{0 . 9 5}$ \\
\hline \multirow{2}{*}{ NP12EO-MA } & $\Delta P$, bar & 0.64 & 0.65 & 0.52 & 0.45 & 0.25 \\
& $\mu^{F}$ app, cP & 65.33 & 66.96 & 53.56 & 45.72 & 25.22 \\
\multirow{2}{*}{ NP12EO-SA } & $\Delta P$, bar & 0.77 & 0.85 & 0.76 & 0.69 & 0.26 \\
& $\mu^{F}{ }_{a p p}, \mathrm{cP}$ & 79.23 & 87.39 & 77.91 & 70.31 & 26.97 \\
\multirow{2}{*}{ NP12EO } & $\Delta P$, bar & 0.45 & 0.44 & 0.49 & 0.27 & 0.06 \\
& $\mu^{F}{ }_{\text {app }}, \mathrm{cP}$ & 30.06 & 30.44 & 33.75 & 18.85 & 4.13 \\
\hline
\end{tabular}

Apparent viscosities of foams were compared at the same $f_{g}=0.5$ to apparent viscosity of nitrogen and water mixture (Figure 8). The gas-water system, due to multiphase flow, creates filtration resistance; however, the addition of surfactant decreases the surface tension and energy required to create more surface area between gas and water, which led to increasing apparent viscosity of more than five times. 


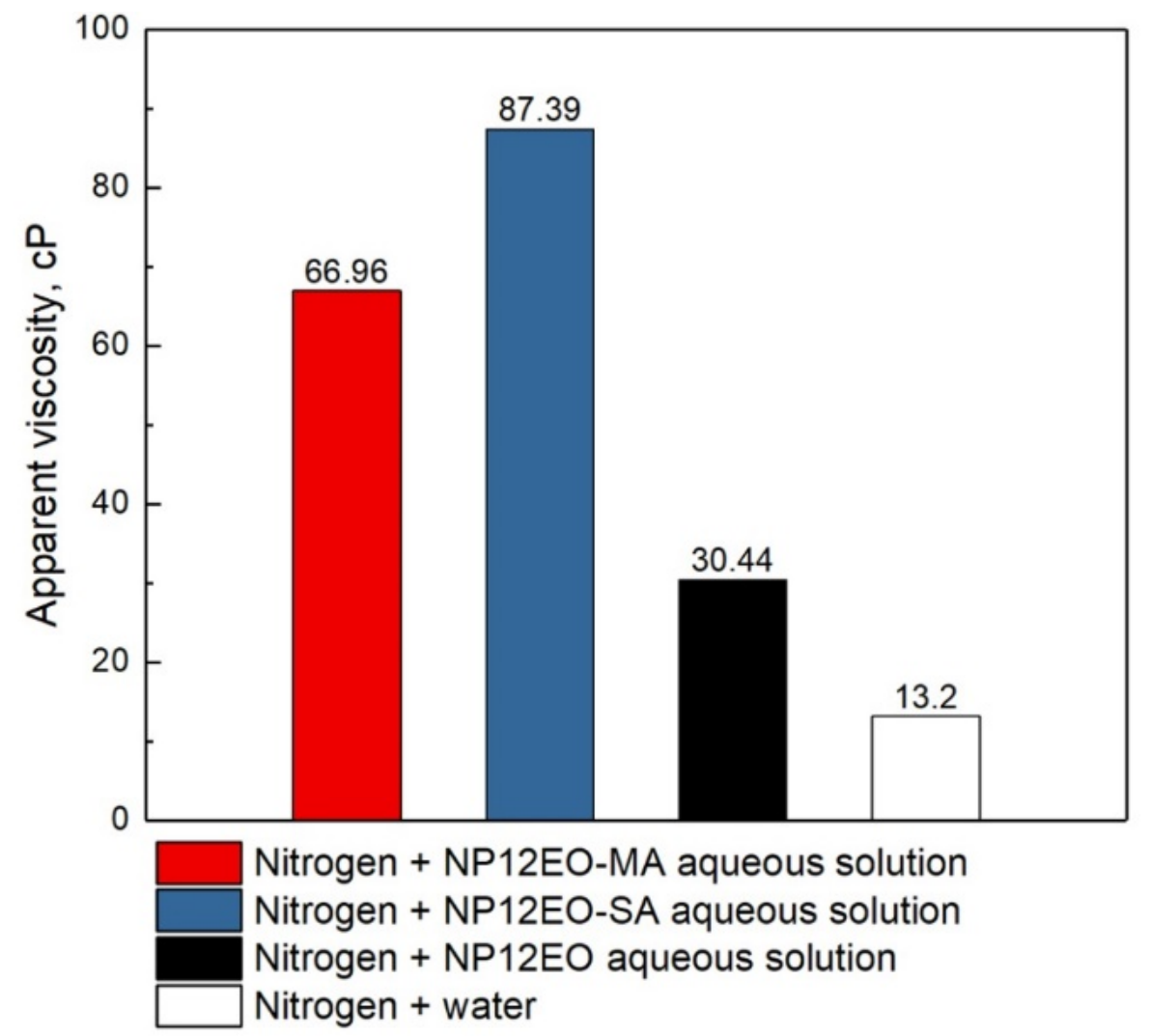

Figure 8. Comparison of apparent viscosities of gas/liquid systems in filtration experiments at $f_{g}=0.5$.

\section{Conclusions}

In this work, new surfactants for foam EOR for high-salinity conditions were developed. Laboratory bulk tests and filtration experiments of two novel anionic-nonionic carboxylate surfactants based on nonylphenol ethoxylate were provided:

1. The addition of the carboxyl group increases the repulsion force of the surfactants which led to increasing foam rate, compared to the nonionic NP12EO. Bulk tests showed that both anionic-nonionic surfactants retain 1.3 times higher foam rate at $20 \% \mathrm{NaCl}$ concentration water than nonionic NP12EO. Moreover, due to nonionic ethoxylate (12) part, modified surfactants retained good solubility and long-term stability in water with $\mathrm{NaCl}$ concentration up to $20 \%$;

2. According to surface tension measurements, synthesized surfactants have less than $0.025 \mathrm{CMC}$. Both $\mathrm{CMC}$ and surface tension at $\mathrm{CMC}$ point $\left(\gamma_{\mathrm{CMC}}\right)$ decrease with $\mathrm{NaCl}$ concentration increasing;

3. Both synthesized surfactants showed higher apparent viscosities than the initial nonionic NP12EO nonionic surfactant aqueous solution at all ranges of foam quality;

4. Although, bulk tests did not show a significant difference in foam rate and half-life time between NP12EO-SA and NP12EO-MA surfactants, the lower apparent viscosity of NP12EO-MA surfactant was achieved in the filtration experiments, which reveals the negative effect of the unsaturated bond in the carboxylic group. Presumably, the presence of an unsaturated bond in the carboxylic part of NP12EO-MA increases surfactant packing surface area due to molecule geometry. This decreases the adsorption rate of surfactant molecules in the interfacial layer and foaming ability; and

5. Both surfactants can be produced using relatively cheap and widely used reagents in a simple two-step synthesis, which makes them prospective candidates for chemical EOR from the economic side of view. 
Author Contributions: Conceptualization, E.R.S. and R.S.P.; methodology, S.Z. and S.A.S.; formal analysis, S.Y.I.; investigation, S.Z. and D.A.Z.; resources, R.S.P. and U.Z.M.; writing-original draft preparation, E.R.S. and C.Y.; writing-review and editing, E.R.S., S.Z. and D.A.Z.; supervision, E.R.S.; project administration, M.A.V.; funding acquisition, M.A.V. All authors have read and agreed to the published version of the manuscript.

Funding: This work was funded by the subsidy allocated to the Kazan Federal University for the state assignment in the sphere of scientific activities (Project No. 0671-2020-0048 of State Assignment No. 075-00216-20-05 of 04.06.2020 (Part II Section 1)).

Conflicts of Interest: The authors declare no conflict of interest.

\section{References}

1. Zhao, L.; Chen, X.; Zou, H.; Liu, P.; Liang, C.; Zhang, N.; Li, N.; Luo, Z.; Du, J. A review of diverting agents for reservoir stimulation. J. Pet. Sci. Eng. 2020, 187, 106734. [CrossRef]

2. Kibodeaux, K.R.; Zeilinger, S.C.; Rossen, W.R. Sensitivity study of foam diversion processes for matrix acidization. In Proceedings of the Proceedings-SPE Annual Technical Conference and Exhibition, New Orleans, LA, USA, 25-28 September 1994; pp. 347-358.

3. Sönmez, A.; Verşan Kök, M.; Özel, R. Performance analysis of drilling fluid liquid lubricants. J. Pet. Sci. Eng. 2013, 108, 64-73. [CrossRef]

4. Blaker, T.; Aarra, M.G.; Skauge, A.; Rasmussen, L.; Celius, H.K.; Martinsen, H.A.; Vassenden, F. Foam for gas mobility control in the Snorre field: The FAWAG project. SPE Reserv. Eval. Eng. 2002, 5, 317-323. [CrossRef]

5. Hanssen, J.E.; Dalland, M. Gas-Blocking Foams. In Foams: Fundamentals and Applications in the Petroleum Industry; American Chemical Society: Washington, WA, USA, 1994; pp. 319-353; ISBN 9780841227194.

6. Deng, X.; Kamal, M.S.; Patil, S.; Hussain, S.M.S.; Zhou, X. A Review on Wettability Alteration in Carbonate Rocks: Wettability Modifiers. Energy Fuels 2020, 34, 31-54. [CrossRef]

7. Yao, Y.; Wei, M.; Kang, W. A review of wettability alteration using surfactants in carbonate reservoirs. Adv. Colloid Interface Sci. 2021, 294, 102477. [CrossRef]

8. Ahmadi, M.A.; Zendehboudi, S.; Shafiei, A.; James, L. Nonionic surfactant for enhanced oil recovery from carbonates: Adsorption kinetics and equilibrium. Ind. Eng. Chem. Res. 2012, 51, 9894-9905. [CrossRef]

9. Ahmadi, M.A.; Shadizadeh, S.R. Experimental investigation of adsorption of a new nonionic surfactant on carbonate minerals. Fuel 2013, 104, 462-467. [CrossRef]

10. Chen, Y.; Elhag, A.S.; Poon, B.M.; Cui, L.; Ma, K.; Liao, S.Y.; Reddy, P.P.; Worthen, A.J.; Hirasaki, G.J.; Nguyen, Q.P.; et al. Switchable nonionic to cationic ethoxylated amine surfactants for $\mathrm{CO}_{2}$ enhanced oil recovery in high-temperature, high-salinity carbonate reservoirs. SPE J. 2014, 19, 249-259. [CrossRef]

11. Ayirala, S.C.; Boqmi, A.; Alghamdi, A.; AlSofi, A. Dilute surfactants for wettability alteration and enhanced oil recovery in carbonates. J. Mol. Liq. 2019, 285, 707-715. [CrossRef]

12. Pu, W.F.; Du, D.J.; Tang, Y.L.; Wang, S. Synthesis of an Alkyl Polyoxyethylene Ether Sulfonate Surfactant and Its Application in Surfactant Flooding. J. Surfactants Deterg. 2018, 21, 687-697. [CrossRef]

13. Arkhipov, V.P.; Filippov, A. The cloud point of aqueous solutions of ethoxylated monoalkylphenols in the individual state and in the presence of electrolytes. J. Dispers. Sci. Technol. 2018, 39, 1442-1446. [CrossRef]

14. Kumar, S.; Mandal, A. Investigation on stabilization of $\mathrm{CO}_{2}$ foam by ionic and nonionic surfactants in presence of different additives for application in enhanced oil recovery. Appl. Surf. Sci. 2017, 420, 9-20. [CrossRef]

15. Chen, Y.; Elhag, A.S.; Cui, L.; Worthen, A.J.; Reddy, P.P.; Noguera, J.A.; Ou, A.M.; Ma, K.; Puerto, M.; Hirasaki, G.J.; et al. $\mathrm{CO}_{2}$-in-water foam at elevated temperature and salinity stabilized with a nonionic surfactant with a high degree of ethoxylation. Ind. Eng. Chem. Res. 2015, 54, 4252-4263. [CrossRef]

16. Jian, G.; Alcorn, Z.; Zhang, L.; Puerto, M.C.; Soroush, S.; Graue, A.; Biswal, S.L.; Hirasaki, G.J. Evaluation of a Nonionic Surfactant Foam for $\mathrm{CO}_{2}$ Mobility Control in a Heterogeneous Carbonate Reservoir. SPE J. 2020, 25, 3481-3493. [CrossRef]

17. Myers, D. Surfactant Science and Technology, 3rd ed.; John Wiley \& Sons: Hoboken, NJ, USA, 2005.

18. Li, Y.; Zhang, P.; Zhao, G.Q.; Cao, X.L.; Wang, Q.W.; Wang, H.Y. Effect of equilibrium and dynamic surface activity of surfactant on foam transport in porous medium. Colloids Surf. A Physicochem. Eng. Asp. 2006, 272, 124-129. [CrossRef]

19. Maguire, R.J. Review of the persistence of nonylphenol and nonylphenol ethoxylates in aquatic environments. Water Qual. Res. J. Can. 1999, 34, 37-78. [CrossRef]

20. Lee Ferguson, P.; Bopp, R.F.; Chillrud, S.N.; Aller, R.C.; Brownawell, B.J. Biogeochemistry of nonylphenol ethoxylates in urban estuarine sediments. Environ. Sci. Technol. 2003, 37, 3499-3506. [CrossRef] [PubMed]

21. Quina, F.H.; Hinze, W.L. Surfactant-mediated cloud point extractions: An environmentally benign alternative separation approach. Ind. Eng. Chem. Res. 1999, 38, 4150-4168. [CrossRef]

22. Dong, R.; Hao, J. Complex fluids of poly(oxyethylene) monoalkyl ether nonionic surfactants. Chem. Rev. 2010, 110, 4978-5022. [CrossRef] 
23. Materna, K.; Milosz, I.; Miesiac, I.; Cote, G.; Szymanowski, J. Removal of phenols from aqueous streams by the cloud point extraction technique with oxyethylated methyl dodecanoates as surfactants. Environ. Sci. Technol. 2001, 35, 2341-2346. [CrossRef]

24. Abdul, A.S.; Gibson, T.L.; Rai, D.N. Selection of Surfactants for the Removal of Petroleum Products from Shallow Sandy Aquifers. Groundwater 1990, 28, 920-926. [CrossRef]

25. Negin, C.; Ali, S.; Xie, Q. Most common surfactants employed in chemical enhanced oil recovery. Petroleum 2017, 3, $197-211$. [CrossRef]

26. Gang, H.Z.; He, X.; He, X.; Bao, X.; Liu, J.; Yang, S.; Li, Y.; Mu, B.Z. Interfacial properties and salt tolerance of carboxylated nonylphenol ethoxylate surfactants. Colloids Surf. A Physicochem. Eng. Asp. 2021, 616, 126222. [CrossRef]

27. Song, X.; Dong, L.; Cao, X.; Xu, Z.; Wang, C.; Zhang, L.; Zhang, L.; Zhao, S. Dynamic interfacial tensions of p-(n-lauryl)-benzyl polyoxyethylene ether carboxybetaine solutions. J. Pet. Sci. Eng. 2014, 124, 27-34. [CrossRef]

28. Guo, L.; Liu, Y.; Hu, S.S.; Xu, Z.C.; Gong, Q.T.; Zhang, L.; Zhang, L. Dynamic interfacial tensions of alkyl alcohol polyoxypropyleneoxyehtylene ether sulfonate solutions. J. Pet. Sci. Eng. 2016, 141, 9-15. [CrossRef]

29. Jayanti, S.; Britton, L.N.; Dwarakanath, V.; Pope, G.A. Laboratory evaluation custom-designed surfactants to remediate NAPL source zones. Environ. Sci. Technol. 2002, 36, 5491-5497. [CrossRef] [PubMed]

30. Stellner, K.L.; Scamehorn, J.F. Surfactant precipitation in aqueous solutions containing mixtures of anionic and nonionic surfactants. J. Am. Oil Chem. Soc. 1986, 63, 566-574. [CrossRef]

31. Croce, V.; Patrolecco, L.; Polesello, S.; Valsecchi, S. Extraction of nonylphenol and nonylphenol ethoxylates from river sediments: Comparison of different extraction techniques. Chromatographia 2003, 58, 145-149. [CrossRef]

32. Sun, L.; Bai, B.; Wei, B.; Pu, W.; Wei, P.; Li, D.; Zhang, C. Recent advances of surfactant-stabilized $\mathrm{N}_{2} / \mathrm{CO}_{2}$ foams in enhanced oil recovery. Fuel 2019, 241, 83-93. [CrossRef]

33. Wang, L.C.; Wang, X.S.; Zhang, J.C.; Song, X.W.; Cao, X.L.; Li, Z.Q. Synthesis and Interfacial Activity of Nonyl Phenol Polyoxyethylene Ether Carboxylate. J. Dispers. Sci. Technol. 2014, 35, 641-646. [CrossRef]

34. Liu, Z.; Zhang, L.; Cao, X.; Song, X.; Jin, Z.; Zhang, L.; Zhao, S. Effect of electrolytes on interfacial tensions of alkyl ether carboxylate solutions. Energy Fuels 2013, 27, 3122-3129. [CrossRef]

35. Standnes, D.C.; Austad, T. Wettability alteration in chalk 2. Mechanism for wettability alteration from oil-wet to water-wet using surfactants. J. Pet. Sci. Eng. 2000, 28, 123-143. [CrossRef]

36. Wang, Y.F.; Huang, J.B. Synthesis and Surface Activity of Alkyl Oxyethylenated Propane Sulfonates. Acta Phys.-Chim. Sin. 2001, 17, 488-490. [CrossRef]

37. Wang, X.; Yan, F.; Li, Z.; Zhang, L.; Zhao, S.; An, J.; Yu, J. Synthesis and surface properties of several nonionic-anionic surfactants with straight chain alkyl-benzyl hydrophobic group. Colloids Surf. A Physicochem. Eng. Asp. 2007, 302, 532-539. [CrossRef]

38. Farajzadeh, R.; Andrianov, A.; Krastev, R.; Hirasaki, G.J.; Rossen, W.R. Foam-oil interaction in porous media: Implications for foam assisted enhanced oil recovery. Adv. Colloid Interface Sci. 2012, 183-184, 1-13. [CrossRef] [PubMed]

39. Sood, A.K.; Aggarwal, M. Evaluation of micellar properties of sodium dodecylbenzene sulphonate in the presence of some salts. J. Chem. Sci. 2018, 130, 39. [CrossRef]

40. Farajzadeh, R.; Krastev, R.; Zitha, P.L.J. Foam films stabilized with alpha olefin sulfonate (AOS). Colloids Surf. A Physicochem. Eng. Asp. 2008, 324, 35-40. [CrossRef]

41. Rudyk, S.; Al-Khamisi, S.; Al-Wahaibi, Y.; Afzal, N. Internal Olefin Sulfonate Foam Coreflooding in Low-Permeable Limestone at Varying Salinity. Energy Fuels 2019, 33, 8374-8382. [CrossRef]

42. Boersma, D.M.; Hagoort, J. Displacement characteristics of nitrogen vs. methane flooding in volatile-oil reservoirs. SPE Reserv. Eng. 1994, 9, 261-265. [CrossRef]

43. Hou, Q.; Zhu, Y.; Luo, Y.; Weng, R.; Jian, G. Studies on nitrogen foam flooding for conglomerate reservoir. In Proceedings of the SPE EOR Conference at Oil and Gas West Asia, Muscat, Oman, 16-18 April 2012; Volume 1, pp. 58-62. [CrossRef]

44. Liang, S.; Hu, S.; Li, J.; Xu, G.; Zhang, B.; Zhao, Y.; Yan, H.; Li, J. Study on EOR method in offshore oilfield: Combination of polymer microspheres flooding and nitrogen foam flooding. J. Pet. Sci. Eng. 2019, 178, 629-639. [CrossRef]

45. Farajzadeh, R.; Andrianov, A.; Zitha, P.L.J. Investigation of immiscible and miscible foam for enhancing oil recovery. Ind. Eng. Chem. Res. 2010, 49, 1910-1919. [CrossRef]

46. Jones, S.A.; van der Bent, V.; Farajzadeh, R.; Rossen, W.R.; Vincent-Bonnieu, S. Surfactant screening for foam EOR: Correlation between bulk and core-flood experiments. Colloids Surf. A Physicochem. Eng. Asp. 2016, 500, 166-176. [CrossRef]

47. Giribabu, K.; Reddy, M.L.N.; Ghosh, P. Coalescence of air bubbles in surfactant solutions: Role of salts containing mono-, di-, and trivalent ions. Chem. Eng. Commun. 2008, 195, 336-351. [CrossRef]

48. Obisesan, O.; Ahmed, R.; Amani, M. The effect of salt on stability of aqueous foams. Energies 2021, 14, 279. [CrossRef]

49. Li, D.; Slattery, J.C. Experimental Support for Analyses of Coalescence. AIChE J. 1988, 34, 862-864. [CrossRef]

50. Sun, L.; Wei, P.; Pu, W.; Wang, B.; Wu, Y.; Tan, T. The oil recovery enhancement by nitrogen foam in high-temperature and high-salinity environments. J. Pet. Sci. Eng. 2016, 147, 485-494. [CrossRef]

51. Ren, Z.H. Mechanism of the Salt Effect on Micellization of an Aminosulfonate Amphoteric Surfactant. Ind. Eng. Chem. Res. 2015, 54, 9683-9688. [CrossRef]

52. Qin, X.; Liu, M.; Zhang, X.; Yang, D. Proton NMR based investigation of the effects of temperature and NaCl on micellar properties of CHAPS. J. Phys. Chem. B 2011, 115, 1991-1998. [CrossRef] 
53. Hussain, S.M.S.; Fogang, L.T.; Kamal, M.S. Synthesis and performance evaluation of betaine type zwitterionic surfactants containing different degrees of ethoxylation. J. Mol. Struct. 2018, 1173, 983-989. [CrossRef]

54. Zhang, L.; Somasundaran, P.; Maltesh, C. Electrolyte effects on the surface tension and micellization of n-dodecyl $\beta$-D-maltoside solutions. Langmuir 1996, 12, 2371-2373. [CrossRef]

55. Jiang, N.; Yu, X.; Sheng, Y.; Zong, R.; Li, C.; Lu, S. Role of salts in performance of foam stabilized with sodium dodecyl sulfate. Chem. Eng. Sci. 2020, 216, 115474. [CrossRef]

56. Cubaud, T.; Ulmanella, U.; Ho, C.M. Two-phase flow in microchannels with surface modifications. Fluid Dyn. Res. 2006, $38,772$. [CrossRef]

57. Gu, M.; Mohanty, K.K. Rheology of polymer-free foam fracturing fluids. J. Pet. Sci. Eng. 2015, 134, 87-96. [CrossRef]

58. Zarei, M.; Aalaie, J. Application of shear thickening fluids in material development. J. Mater. Res. Technol. 2020, 9, 10411-10433. [CrossRef] 